Board of Governors of the Federal Reserve System

International Finance Discussion Papers

Number 648

October 1999

\title{
WHEN WOULD EDUCATIONAL STANDARDS HELP IMPROVE SCHOLASTIC ACHIEVEMENT?
}

\author{
Murat F. Iyigun
}

NOTE: International Finance Discussion Papers are preliminary materials circulated to stimulate discussion and critical comment. References in publications to International Finance Discussion Papers (other than an acknowledgment that the writer has had acccess to unpublished material) should be cleared with the author or authors. Recent IFDPs are available on the Web at www.bog.frb.fed.us. 


\title{
WHEN WOULD EDUCATIONAL STANDARDS HELP IMPROVE SCHOLASTIC ACHIEVEMENT?
}

\author{
Murat F. Iyigun*
}

\begin{abstract}
I study the potential effects of setting mandatory standards in primary and secondary education on student performance. To that end, I present a model in which investment in education is indivisible. Thus, if demand exceeds supply at any level of education, allocation is carried out-at least in part-via test scores. The model highlights how the effectiveness of educational standards in altering student performance depends on the college and secondary school education premia, the stringency of standards, and the supply of college education-factors which together determine the competitiveness of college admissions. A relatively high college education premium raises the incentive to finish high school and apply to college, but the marginal benefit of meeting standards or the cost of non-compliance depend on the secondary education premium. Thus, the effect of raising educational standards on student performance may be relatively small when the secondary education premium is relatively low. Moreover, when the supply of higher education is relatively abundant so that college entrance is a non-competitive process, students' incentive to make their best effort diminishes, and in that case, the role of education premia-and therefore of standards-as incentives may be limited.
\end{abstract}

keywords: tests, student performance, education premia.

* The author is staff economist in the Division of International Finance, Board of Governors of the Federal Reserve System. He would like to thank Andrew T. Levin and Ann L. Owen for helpful comments. The views in this paper are solely the responsibility of the authors and should not be interpreted as reflecting the views of the Board of Governors of the Federal Reserve System or of any other person associated with the Federal Reserve System. Please send all correspondence to: The Board of Governors of the Federal Reserve System, Mail Stop 23, Washington, D.C. 20551. E-mail: Murat.Iyigun@frb.gov. 
"The education equivalent is...millions of separate decisions not to press oneself hard at academic pursuits and thus not learn much in school, confident that one's access to the good life will be unimpaired." [from "We Must Take Charge: Our Schools and Our Future" by C. E. Finn. Jr. (1991, p. 112), emphasis added.]

\section{Introduction}

The publication of $A$ Nation at Risk in 1983 marked a watershed in the educational policy debate in the United States. This report of the National Commission on Excellence in Education aimed to highlight what had gone wrong with the U. S. K-12 educational system and to warn the nation that its future prospects were dim. In language highly reflective of the political themes that dominated the era, the report argued that the society's prevalent acceptance of mediocrity in student performance was synonymous with unilateral national disarmament. It read "If an unfriendly foreign power had attempted to impose on America the mediocre educational performance that exists today, we might well have viewed it as an act of war."

A Nation at Risk was the culmination of growing public discontent with student performance. While the U. S. education system had been the focus of public policy discussions earlier in the $1950 \mathrm{~s}$ and the $1960 \mathrm{~s},{ }^{1}$ no hard evidence existed to support the notion that student performance in the United States was deteriorating. That came in 1975, when the College Board disclosed that the average score on its Scholastic Aptitude Test (SAT)-later renamed the Scholastic Achievement Test to reflect some changes in content-had been declining for more than a decade. Data from international achievement tests also indicated that American children and teenagers lagged behind those of other industrialized nations in core subjects such as math and science. ${ }^{2}$ In the period which followed, data showing unsatisfactory student performance in the United States was ubiquitous. By the mid-1980s, a reform movement had gained sufficient momentum that, as Ravitch (1983) reports, thirty eight legislatures had ordered their public schools to administer minimum competency tests in basic skills. Around the same time, many

\footnotetext{
${ }^{1}$ Highlighted, for example, by the publication of the Coleman (1966) report by the U. S. Department of Education.

${ }^{2}$ Lapointe, Mead and Phillips (1989).
} 
more fundamental types of school reform were either being contemplated or introduced in various jurisdictions.

Inasmuch as improving student achievement is the main objective, it should come as no surprise that the most common element in school reform agendas was-and for the most part continues to be-the introduction of mandatory or voluntary standards of minimum student performance. In fact, all but five states raised their graduation requirements between 1980 and 1990. More recently, the Goals 2000: Educate America Act was signed into law in 1994 and amended in 1996. It made explicit the objective of establishing voluntary national education standards, or alternatively "what students should know and be able to do." Since then, forty-seven states plus the District of Columbia and Puerto Rico have adopted comprehensive Goals 2000 education reform plans, and of those, eighteen have explicitly defined student performance standards.

After more than a decade and a half since some pioneering states' adoption of minimum standards of student performance, however, fundamental questions remain: Is the introduction of national standards of education a panacea to reverse the trends in student achievement in the United States? Even if the answer to that is a 'Yes' as many claim, ${ }^{3}$ what are the economic conditions under which the imposition of educational standards would be most effective? On the one hand, the available data, which remain sketchy, seem to suggest that some progress has been made. For example, Finn (1991) notes that between 1980 and 1990 when most states raised their graduation requirements, "practically every student who stayed in school reached the 'rudimentary' level of achievement, all but a handful met the (slightly higher) 'basic' level of skills in reading and math," and dropout rates continued to decline-despite some expectations to the contrary. On the other hand, improvements in student performance have been marginal at best, ${ }^{4}$ and preceded the introduction of stricter graduation requirements. Moreover, they came at a time when educational incentives were being altered dramatically. After rising in the 1960s and declining in the 1970s, the return to higher education, as well as other components of skill, started to increase rapidly in the early 1980s. In fact, the returns to

\footnotetext{
${ }^{3}$ See, for example, Sizer (1995) and Ravitch (1995).

${ }^{4} \mathrm{~A}$ recent comprehensive worldwide comparison of educational standards-The Third International Mathematics and Science Study-found that, out of 21 countries, the United States ranked 16th in general science, 19th in math and last in physics (The Economist, September 4, 1999, p. 33).
} 
higher education soared so impressively during the 1980s and the early 1990s that in 1994 it stood roughly 35 percent above its value in 1963. In addition, between the late 1970s and mid-1980s when the return to education, experience and other components of unobservable skill were rising, the increase in the education premium outpaced that in the returns to experience and other components of skill. ${ }^{5}$

Determining the appropriate public policy response to poor student performance is important due to what may be at stake. Furthermore, improvements in student performance may yield direct benefits, such as higher labor productivity and efficiency, but may also have other-more subtle but still important-economic repercussions, like lower income inequality and higher intergenerational economic mobility.

In what follows, I illustrate how the potential benefit of educational standards is inextricably linked to the interplay of many factors, such as the college and high-school education premia, the accessibility of higher education, and the stringency of standards. My key findings can be summarized as follows: First, the personal benefit and cost to students of meeting standards hinge critically upon the education premia; a high college premium raises the incentive to finish high school and apply to college, but the marginal benefit of meeting standards-or, alternatively, the cost of non-compliance-is related to the secondary (high-school) education premium. Thus, ceteris paribus, the model below demonstrates that it is not reasonable to expect standards to affect educational outcomes in a significant way when the high-school education premium is relatively low. Second, the accessibility of college education matters. When the supply of college education is sufficiently abundant that getting a college degree is not a competitive process, students' incentive to make their best effort diminishes. Thus, in that case, the imposition of educational standards may have a limited effect on student performance. Third, the stringency of standards affect student effort, although its ultimate impact depends on other factors such as the education premia and the accessibility of higher education.

Despite the continued preoccupation of educational experts and the U. S. public with the potential impact of educational standards on student performance, there exists few studies in the economic literature on how the setting of standards may interact with economic incentives to determine the effectiveness of the former. There are two

\footnotetext{
${ }^{5}$ See Autor, Katz and Krueger (1998), Juhn et al. (1993) and Murphy (1996).
} 
main exceptions: Betts (1998) challenges the notion that a policy maker concerned with inequality may desire to set low educational standards in order to avoid less able students from dropping out of school. His central finding is that when standards are higher and more students choose to drop out in response, the wages of all types of labor may increase: High-ability workers continue to graduate from school but they expend more study effort which raises their productivity, and when lower-ability workers choose to drop out, their earnings also increase due to the fact that firms now realize that the average ability (and hence productivity) of drop-outs are higher as well. Costrell (1994) shows that optimal educational standards do not necessarily fall with increased preference for leisure, heterogeneity or nonstudent inputs to education. More relevantly, he demonstrates that although increases in the education premium due to skill-biased technological change may increase the opportunity cost of dropping out, they also raise the incentives to meet standards. Consequently, he notes that optimal educational standards may be non-decreasing in skill-biased technological change. The findings I present below are both consistent with and complementary to those of Costrell: They demonstrate that increases in the higher education premium may help boost students' incentive to meet standards, and therefore, their study effort. They also indicate, however, that this effect depends on the accessibility of higher education and that the marginal effect of raising educational standards depends on the secondary education premium and the stringency of standards imposed.

The remainder of the paper is organized as follows: In section 2, I define the economy and the individuals' preferences. In section 3, I examine student performance in a model in which there are no national educational standards. In section 4, I discuss how the incorporation of mandatory standards of performance may affect scholastic achievement, educational attainment and dropout rates. In Section 5, I make some further observations and discuss their implications. And in section 6, I summarize and conclude.

\section{The Economy, Preferences, and the Allocation of Education}

Consider a simple economy in which there is a single consumption good. Individuals live for three periods and they are endowed with one unit of time in each period. The size of 
the population is normalized to one and there is no population growth. In the first period, individuals attend primary and secondary schools. They are required to attend and finish primary school but they are not required to complete their secondary education. ${ }^{6}$ In the second period, those who have completed their secondary school studies in the first period attend college if they gain admission. In the third and final period, individuals work and consume. ${ }^{7}$ Their preferences, which are identical, are defined over expected consumption in the final period and leisure time in the first period. There is no time discounting. Preferences are represented by

$$
u_{i}=E\left[\ln c_{i}\right]+\ln l_{i}
$$

where $c_{i}$ denotes $i$ 's consumption in the final period and $l_{i}$ denotes his leisure in the first period. By construction, the amount of leisure time is inversely related to the amount of time individuals spend studying in the first period. That is, $l_{i} \leq 1-\tau_{i}$ where $\tau_{i}$, $0 \leq \tau_{i} \leq 1$, denotes the time individual $i$ devotes to study effort in the first period.

For any given level of education, an individual $i$ 's labor productivity, $\Omega_{i}$, depends on the amount of study effort he exerts in school, $\tau_{i}$, and his innate ability, $A_{i}$ :

$$
\Omega_{i}=\tau_{i} A_{i}
$$

I assume that $p, 0<p<1$, fraction of the individuals are high ability, $\bar{A}$, and $1-p$ are low ability, $\underline{A}$. For the remainder of the analysis, I will also assume that (a) the supply of educational services at all levels are fixed, and that, (b) while the supply of public education up to and including the secondary level is abundant enough to school everyone in the economy, that of higher education, henceforth denoted by $\bar{S}$, is strictly less than one.

\footnotetext{
${ }^{6}$ This assumption is consistent with mandatory education laws in many industrialized counrties. It is also in line with those in the United States which mandate schooling until 18 years of age but do not actually require the completion of a certain grade level.

${ }^{7}$ Implicit in this formulation are the assumption that high school graduates and dropouts do nothing in the second period and the abstraction from any out-of-pocket expenses associated with education. Both are inconsequential to the qualitative nature of the results presented below.
} 
Given that the supply of higher education is strictly less than one, there exist the possibility that its demand exceeds the supply. In that case applicants are admitted to schools based on their measurable productive abilities. ${ }^{8}$ However, the available screening technology is imperfect. ${ }^{9}$ Let $I_{i}, I_{i}: R_{+}^{3} \rightarrow R$, denote the $\log$ of $i$ 's potential productivity as measured with the available proxy. Then,

$$
I_{i}=a_{i}+e_{i}+\varepsilon_{i}
$$

where $a_{i} \equiv \log A_{i}\left(\right.$ with $a_{i}=\underline{a}$ or $\left.\bar{a}\right), e_{i} \equiv \log \tau_{i}$ and where $\varepsilon_{i}$ represents the log-normally distributed measurement error term, $\varepsilon_{i} \sim N(0,1)$.

Let $I^{*}$ denote the minimum test score required for college admission. Given that college admission is based on test score results, the following equality must hold:

$$
\bar{S}=1-\Psi\left(\varepsilon^{*}\right)
$$

where $\Psi\left(\varepsilon^{*}\right), \Psi\left(\varepsilon^{*}\right) \equiv p \Phi\left(I^{*}-\bar{a}-e_{\bar{A}}\right)+(1-p) \Phi\left(I^{*}-\underline{a}-e_{\underline{A}}\right)$ denotes the population c.d.f. As it is implicit in its definition, the function $\Psi($.$) is a mixture based on each$ ability type's own c.d.f., $\Phi($.$) , with 1-\Psi\left(\varepsilon^{*}\right)$ denoting the fraction of the population which applies and gets admitted to college.

[Figure 1 about here.]

Taken together, (3) and (4) imply that the threshold test score required for college admission, $I^{*}$, is a function of the supply of educational services, $\bar{S}$, and the distribution of test scores, $\Psi($.$) . The test score distribution \Psi($.$) is, in turn, determined by individ-$ uals' abilities, their study effort, and the fraction of high- and low-ability students (as determined by $p$ ).

\footnotetext{
${ }^{8}$ For sake of simplicity, I also abstract from any cost associated with screening.

${ }^{9}$ The imperfect observability of ability and effort, too, is non-essential for the qualititaive nature of the result shown below, although they are important in simplifying the analysis and exposition.
} 
Lemma 1: For any given level of student effort, $e_{i}, i=\underline{A}, \bar{A}$, the cutoff test score required for college admission, $I^{*}$, is decreasing in the supply of higher education, $\bar{S}$.

Proof: Follows immediately from (4):

$$
\frac{\partial I^{*}}{\partial \bar{S}}=-\frac{1}{p \phi\left(I^{*}-\bar{a}-e_{\bar{A}}\right)+(1-p) \phi\left(I^{*}-\underline{a}-e_{\underline{A}}\right)}<0 .
$$

Now let $\omega$ represent the wage rate per efficiency units of labor, where

$$
\omega= \begin{cases}w^{c} & \text { for college graduates } \\ w^{h} & \text { for high school graduates } \\ w^{d} & \text { for others. }\end{cases}
$$

Thus, if individual $i$ completes secondary school and applies for admission to college, then $i$ gets a college education and earns $\tau_{i} A_{i} w^{c}$ in the third period if and only if $i$ 's potential productivity as measured with the available proxy, $I_{i}$, is greater than or equal to the threshold level $I^{*}$. If $i$ completes secondary school but either chooses not to attend college or fails to be admitted because he scores below $I^{*}$, then he earns $\tau_{i} A_{i} w^{h}$ in the final period. Otherwise, if he chooses not to attend or drops out of secondary school in the second period, he gets $\tau_{i} A_{i} w^{d}{ }^{10}$

\section{Student Effort and Academic Achievement without Educational Standards}

Without any academic standards to meet, all individuals who wish to complete their secondary school education can do so. Regardless of their educational choice, individuals solve the following problem:

\footnotetext{
${ }^{10}$ This formulation is consistent with the assumption that the size of the student cohort under consideration is a relatively small segment of the labor market so that their choices have a negligible impact on prevailing wage rates. Alternatively, one could interpret the benefit of secondary and college education on labor productivity as being constant due to no complementarity in aggregate production among labor of different education types. In section 5, I discuss the potential implications of wage rates being affected by workers' educational choices.
} 


$$
\max _{\tau_{i}} E\left[\ln c_{i}\right]+\ln l_{i}
$$

taking as given others' study effort, $\tau_{j}, j \neq i$, subject to $l_{i} \leq 1-\tau_{i},(2),(3)$ and (4) with

$$
E\left[\ln c_{i}\right] \leq E\left[\ln y_{i}\right]=\ln \left(\tau_{i} A_{i}\right)+\left[1-\Phi\left(\varepsilon_{i}^{*}\right)\right] \ln w^{c}+\Phi\left(\varepsilon_{i}^{*}\right) \ln w^{h},
$$

if individuals choose to attend and finish secondary school, or

$$
E\left[\ln c_{i}\right]=\ln c_{i} \leq \ln y_{i}=\ln \left(\tau_{i} A_{i} w^{d}\right)
$$

if they choose not to attend secondary school. While equation (7) indicates that an individual $i$ ' payoff from getting a secondary school degree depends on $i$ 's expected odds of college admission, (8) shows that there exists no uncertainty in the payoffs when $i$ chooses not to graduate from secondary school. Let $\tau_{i}^{n}, i=\underline{A}, \bar{A}$, denote the optimal amount of effort individual $i$ needs to exert when he chooses to finish secondary school and apply for college admission, and let $I^{n}, I^{n} \equiv I^{*}$, denote the cutoff exam score required for college admission when no educational standards exist (with $\varepsilon_{i}^{n}$ analogously representing the measurement error term above which admission is guaranteed). Then,

$$
\tau_{i}^{n}=\frac{1+\phi\left(\varepsilon_{i}^{n}\right) \ln \left(w^{c} / w^{h}\right)}{2+\phi\left(\varepsilon_{i}^{n}\right) \ln \left(w^{c} / w^{h}\right)} \geq \frac{1}{2} ; \quad i=\underline{A}, \bar{A},
$$

where $\tau_{i}^{n} \in[1 / 2,1)$, and where equation (9) implicitly defines $\tau_{i}^{n}$ since $\varepsilon_{\underline{A}}^{n}=I^{n}-\underline{a}-\log \tau_{\underline{A}}^{n}$ and $\varepsilon_{\bar{A}}^{n}=I^{n}-\bar{a}-\log \tau_{\bar{A}}^{n}$. As we shall see below, the following assumption ensures that both types of students' optimal study effort, $\tau_{i}^{n}$, is unique:

Assumption 1: $1+\log (1 / 2)=0.7 \geq I^{*}\left[\bar{S}, \bar{a}, \underline{a}, p ; e_{\bar{A}}=e_{\underline{A}}=\log (1 / 2)\right]-\underline{a}$ 
Proposition 1: $\forall i=\underline{A}, \bar{A}$, a solution to the maximization problem specified by (2)-(8) exists, is unique, and equals $\tau_{i}^{n}>1 / 2$ iff $\ln \left(\tau_{i}^{n} A_{i} w^{c}\right)-$ $\Phi\left(\varepsilon_{i}^{n}\right) \ln \left(w^{c} / w^{h}\right)+\ln \left(1-\tau_{i}^{n}\right)>\ln \left(A_{i} w^{h}\right)+2 \ln (1 / 2)$.

Proof: Existence follows from the fact that the maximand given by equation (6) is continuous in $\tau_{i}$, equals $-\infty$ when either $\tau_{i}=0$ or $\tau_{i}=1$, and the fact that, at $\tau_{i}=1 / 2$, it attains the value $\ln \left(A_{i} w^{h}\right)+2 \ln (1 / 2)<-\infty$, with $\phi\left(\varepsilon_{i}^{n}\right) \ln \left(\frac{w^{c}}{w^{h}}\right) \geq 0$. Uniqueness is due to the fact that marginal cost is strictly increasing in study effort, $\tau_{i}$, and that under assumption 1, the marginal benefit is decreasing over the relevant range $\tau_{i}^{n} \in[1 / 2,1$ ) (See Figure 2).

[Figure 2 about here.]

For heuristic purposes, it is helpful to first review the equilibrium when the college premium is zero (i.e., $\left.w^{c}=w^{h}\right)$. In that case, although there exists no incentive to get a college education, both types of individuals still find it optimal to exert some positive amount of study effort in secondary school. That is, when $w^{c}=w^{h}, \tau_{i}^{n}=1 / 2$, $i=\underline{A}, \bar{A}$. Of course, the reason students exert effort is not to improve their odds of college admission, which carries no pecuniary benefit as the college education premium is zero, but to be sufficiently productive as secondary school graduates or as dropouts. As long as secondary school graduation is guaranteed-as it would be when there exists no minimum academic requirements for completion-and the secondary school premium is strictly positive (i.e., $w^{h}>w^{d}$ ), all individuals' indirect utility derived from finishing secondary school will exceed that when they choose not to attend or drop out. That is, $w^{h}>w^{d} \Rightarrow \ln \left(A_{i} w^{h}\right)+2 \ln (1 / 2)>\ln \left(A_{i} w^{d}\right)+2 \ln (1 / 2)$, and in equilibrium, both types of individuals attend secondary school but no one finds it optimal to apply to college. ${ }^{11}$ An equally important observation-one which holds even with a strictly positive college

\footnotetext{
${ }^{11}$ In this model, individuals will be indifferent between completing secondary school and dropping out of it if the secondary school education premium is zero (i.e., $w^{h}=w^{d}$ ). It is clear that this is an artifact of the modelling strategy I have chosen to employ because, for simplicity, I have disregarded any cost-beyond the opportunity to drop out and earn $w^{d}$-of attending secondary school. If there were such additional costs, however, the qualitative nature of the results would not have been altered except for the modification that the point of indifference between completion and dropping out would have entailed a higher secondary school wage rate, $w^{h}$, than that paid to unskilled workers, $w^{d}$.
} 
education premium-is that absent mandatory secondary school performance standards, the study effort of any given student still equals $1 / 2$ if the optimal choice is to drop out of secondary school or to finish but not apply to college. Again, the reason for this is guaranteed secondary school graduation, which essentially makes reaping the rewards of a secondary school diploma costless.

In contrast, if the college premium is strictly positive and the secondary school premium is positive (i.e., $w^{c}>w^{h} \geq w^{d}$ ), then it is possible for one or both of the ability types to find it optimal to exert more effort in their secondary school studies in an attempt to raise their college admission odds. As (9) implies, if the college education premium is strictly positive, then $\tau_{i}^{n}>1 / 2, i=\underline{A}, \bar{A}$. Moreover, even when the secondary school education premium is zero (i.e., $w^{h}=w^{d}$ ), a sufficiently high college premium will ensure that individuals complete their secondary education.

Three other observations are also in order. First, using equation (9) and invoking the implicit function theorem we can examine whether higher or lower ability types will spend more study effort in school. That is, we can establish that

$$
\frac{\partial \tau_{i}^{n}}{\partial A_{i}}=\frac{\tau_{i}^{n}}{A_{i}} \frac{2 \varepsilon_{i}^{n} \phi\left(\varepsilon_{i}^{n}\right) \ln \left(w^{c} / w^{h}\right)}{\tau_{i}^{n}\left[2+\phi\left(\varepsilon_{i}^{n}\right) \ln \left(w^{c} / w^{h}\right)\right]^{2}-2 \varepsilon_{i}^{n} \phi\left(\varepsilon_{i}^{n}\right) \ln \left(w^{c} / w^{h}\right)}\left\{\begin{array}{ccc}
>0 & \text { for } \quad \varepsilon_{i}^{n}>0 \\
\leq 0 & \text { for } \quad \varepsilon_{i}^{n} \leq 0
\end{array}\right.
$$

where $\varepsilon_{i}^{n}$ equals $I^{n}-a_{i}-\log \tau_{i}^{n}$, and where due to Assumption 1, the denominator is unambiguously positive. Equation (10) implies that if an individual $i$ 's ability is sufficiently high or the supply of college education is relatively abundant so as to virtually ensure admission to college for a given level of study effort $\tau_{i}^{n}$, then $\varepsilon_{i}^{n}<0, \phi\left(\varepsilon_{i}^{n}\right)$ is close to zero, and the effect of a marginal increase in study effort on $i$ 's college admission is negative and small. Put differently, for higher ability to imply less study effort, either individual $i$ 's ability needs to be sufficiently high or the supply of college education relatively abundant for a given level of study effort $\tau_{i}^{n}$.

Second, regardless of whether the equilibrium study effort, $\tau_{i}^{n}$, is decreasing or increasing in innate ability, $A_{i}$, the average test score of high ability students would exceed that of lower ability ones. That is, even if equilibrium study effort is decreasing 
in innate ability, (i.e., $\partial \tau_{i}^{n} / \partial A_{i}<0$ ), the effect of innate ability on test scores would still dominate that of study effort. Let $\bar{I}_{i}, i=\underline{A}, \bar{A}$, denote average test scores when an interior solution exists for both ability types (i.e., $\forall i=\underline{A}, \bar{A}, \tau_{i}=\tau_{i}^{n}>1 / 2$ ):

Lemma 2: $\forall i=\underline{A}, \bar{A}, \tau_{i} \geq 1 / 2$ and $\bar{I}_{\bar{A}}>\bar{I}_{\underline{A}}$.

Proof: Suppose not. Suppose that $\bar{I}_{\bar{A}} \leq \bar{I}_{\underline{A}}$. Then, $\log (\bar{A} / \underline{A}) \leq \log \left(\tau_{\underline{A}}^{n} / \tau_{\bar{A}}^{n}\right)$ $\Rightarrow \tau_{\underline{A}}^{n}>\tau_{\bar{A}}^{n}$. Without loss of generality, consider the case in which $\bar{I}_{\bar{A}}=$ $\bar{I}_{\underline{A}}$. Using (9) we can then establish that $\varepsilon_{\underline{A}}^{n}=\left[I^{n}-\underline{a}-\log \tau_{\underline{A}}^{n}\right]=\varepsilon_{\bar{A}}^{n}=$ $\left[I^{n}-\bar{a}-\log \tau_{\bar{A}}^{n}\right] \Rightarrow \tau_{\underline{A}}^{n}=\tau_{\bar{A}}^{n}$, in violation of $\tau_{\underline{A}}^{n}>\tau_{\bar{A}}^{n}$.

Third, the effect of an increase in the college education premium on individuals' optimal study effort is unambiguously positive:

$$
\frac{\partial \tau_{i}^{n}}{\partial\left(w^{c} / w^{h}\right)}=\frac{\tau_{i}^{n}}{\left(w^{c} / w^{h}\right)} \frac{\phi\left(\varepsilon_{i}^{n}\right)}{\tau_{i}^{n}\left[2+\phi\left(\varepsilon_{i}^{n}\right) \ln \left(w^{c} / w^{h}\right)\right]^{2}-2 \varepsilon_{i}^{n} \phi\left(\varepsilon_{i}^{n}\right) \ln \left(w^{c} / w^{h}\right)}>0
$$

Thus, as in Costrell (1994), if skill-biased technological change induces the college education premium to rise, it will improve students' incentive to study harder. The following proposition further defines the characteristics of the equilibrium when there exists no national educational standards:

Proposition 2: (i) $\exists \bar{S}<1$ and $w^{c}>w^{h} \geq w^{d}$ s. t. $\forall i=\underline{A}, \bar{A}, \partial \tau_{i}^{n} / \partial A_{i} \geq$ 0 ; (ii) $\forall i=\underline{A}, \bar{A}, \lim _{\bar{S} \rightarrow 1} \tau_{i}^{n}=1 / 2$.

Proof: (i) follows directly from equation (10), and (ii) from (9) and the fact that $\lim _{\bar{S} \rightarrow 1} \phi\left(\varepsilon_{i}^{n}\right)=0$.

Thus, without any educational standards, key factors which affect students' academic effort at the secondary school level-besides their innate abilities-are the college education premium and the availability of higher education. Holding constant students' 
academic effort, both help determine how competitive the college admissions process is: Ceteris paribus, the higher is the college education premium, the more effort students need to exert in an attempt to improve their college admission odds, and the higher is the supply of college education, the easier students qualify for college admissions which lowers their incentive to study harder.

\section{A System with Educational Standards}

The objective of putting in place educational standards is to ensure that all individuals who finish secondary school meet a minimum level of potential labor productivity. Consequently, the adoption of national standards in secondary school education will either force individuals to expend a certain amount of study effort in an attempt to meet the standards (with the required amount being related to innate ability, and therefore, varying across the two ability types), or force those who find it costly to not attend-or drop out of-secondary schools. However, given that those who wish to complete their secondary school education will need to demonstrate a given level of proficiency, the adoption of national standards in education will also be reflected by a minimum score on tests that are used for college admissions screening-a score, most plausibly, below that which determines admissions to college. ${ }^{12}$

As I argue below, the latter turns out not to be a trivial matter. In fact, when the supply of higher education is sufficiently abundant so that college entry is in general a relatively non-competitive process (as it is in the United States), whether the polity is capable of supporting the adoption of educational standards that exceed those required for college admission is critical for standards to have a meaningful influence on student performance. That noted, I will initially maintain the assumption that the upper bound of the secondary school performance standards are given by those necessary for college admission. That is, I will assume $I^{\text {min }} \leq I^{s}$, where $I^{\text {min }}$ denotes the lowest test score acceptable under secondary school education standards, and $I^{s}, I^{s} \equiv I^{*}$, represents the cutoff exam score required for college admission when educational standards exist. Later on, I will also analyze the implications of being able to set secondary education standards that exceed those required for college admission.

\footnotetext{
${ }^{12}$ Alternatively, I could have explicitly assumed that whether students meet the educational standards or not are assessed using the tests which primarly are designed to determine college entrance.
} 
With mandatory national standards of academic performance in place at the secondary school level, individuals continue to maximize equation (6), and the payoff from choosing not to attend secondary school is still given by (8). However, in an educational system with national standards, there exists the possibility that students who do not meet the standards will fail to graduate. Consequently, the constraint introduced in (7) needs to be modified in order to take into account the effect of educational standards on the expected payoff from attending secondary school:

$$
\begin{gathered}
E\left[\ln c_{i}\right] \leq E\left[\ln y_{i}\right]=\ln \left(\tau_{i} A_{i}\right)+\left[1-\Phi\left(\varepsilon_{i}^{s}\right)\right] \ln w^{c}+\left[\Phi\left(\varepsilon_{i}^{s}\right)-\Phi\left(\varepsilon_{i}^{\min }\right)\right] \ln w^{h} \\
+\quad \Phi\left(\varepsilon_{i}^{\min }\right) \ln w^{d}
\end{gathered}
$$

where $\varepsilon_{i}^{s}$ represents the measurement error term above which college admission is guaranteed (the analog of $\varepsilon_{i}^{n}$ in section 3 ), and $\varepsilon_{i}^{\min }$ denotes that associated with the lowest test score acceptable under a system with educational standards. A comparison of equation (12) with (7) reveals that, for any given level of study effort, $i$ 's expected payoff from secondary education declines as a result of the introduction of minimum performance requirements. The obvious reason for this is that the setting of national educational standards raise the probability of failure to graduate from secondary school and earn the associated wage rate, $w^{h}$. In fact, holding constant the study efforts of both types, it is straightforward to see that the difference between (12) and (7) equals - $\Phi\left(\varepsilon_{i}^{\min }\right) \ln \left(w^{h} / w^{d}\right)$, which is the expected income loss associated with the failure to graduate from secondary school. Letting $\tau_{i}^{s}, i=\underline{A}, \bar{A}$, denote the optimal amount of effort individual $i$ exerts when educational standards apply, we can derive the following first-order condition:

$$
\tau_{i}^{s}=\frac{1+\phi\left(\varepsilon_{i}^{n}\right) \ln \left(w^{c} / w^{h}\right)+\phi\left(\varepsilon_{i}^{\min }\right) \ln \left(w^{h} / w^{d}\right)}{2+\phi\left(\varepsilon_{i}^{n}\right) \ln \left(w^{c} / w^{h}\right)+\phi\left(\varepsilon_{i}^{\min }\right) \ln \left(w^{h} / w^{d}\right)} ; \quad i=\underline{A}, \bar{A}
$$

where, as with equation (9), (13) implicitly defines $\tau_{i}^{s}$ since $\varepsilon_{\underline{A}}^{s}=I^{s}-\underline{a}-\log \tau_{\underline{A}}^{s}$ and $\varepsilon_{\bar{A}}^{s}=I^{s}-\bar{a}-\log \tau_{\bar{A}}^{s}$. 
Proposition 3: $\forall i=\underline{A}, \bar{A}$, a solution to the maximization problem specified by (2)-(6), (8) and (12) exists, is unique, and equals $\tau_{i}^{s}>1 / 2$ iff $\ln \left(\tau_{i}^{s} A_{i} w^{c}\right)$ $-\Phi\left(\varepsilon_{i}^{s}\right) \ln \left(w^{c} / w^{h}\right)-\Phi\left(\varepsilon_{i}^{\min }\right) \ln \left(w^{h} / w^{d}\right)+\ln \left(1-\tau_{i}^{s}\right)>\ln \left(A_{i} w^{h}\right)+2 \ln (1 / 2)$.

Proof: Analogous to that of Proposition 1.

When compared with (9), equation (13) reveals how the setting of educational standards might alter student performance. First, the effect of standards on study effort depends positively on how high the standards are set, implicitly given by $\varepsilon_{i}^{\min }$. Second, the net impact of mandatory standards on student performance depends on the secondary education premium, $w^{h} / w^{d}$. In fact, (13) implies that, when an interior solution to the maximization problem exists for both ability types, the optimal study effort under national educational standards, $\tau_{i}^{s}$, is strictly higher than that without such standards, $\tau_{i}^{n}$, and that as the secondary education premium approaches zero (i.e., $w^{h} / w^{d} \rightarrow 1$ ), any effect national educational standards may have on students' academic effort vanishes. Finally, since for any given study effort the maximand specified by (12) has a lower value than that with no educational standards given by (7), and given that the optimal study effort, $\tau_{i}^{s}$, is increasing in the secondary education premium, $w^{h} / w^{d}$, it is possible that not attending secondary school becomes optimal for lower ability students when mandatory standards are put in place. For more extreme parameter values which make the secondary education premium sufficiently high, even high ability students may choose not to attend secondary school.

Proposition 4: (i) $\forall i=\underline{A}, \bar{A}$, if an interior solution to the maximization problem specified by (2)-(6), (8) and (12) exists s.t. $\tau_{i}=\tau_{i}^{s}>1 / 2$, then in equilibrium $\tau_{i}^{s}>\tau_{i}^{n}>1 / 2$; (ii) $\lim _{\left(w^{h} / w^{d}\right) \rightarrow 1} \tau_{i}^{s}=\tau_{i}^{n}$; (iii) $\lim _{I^{\min } \rightarrow-\infty} \tau_{i}^{s}=$ $\tau_{i}^{n}$; (iv) $\forall \bar{S}<1$ and $w^{c} \geq w^{h} \geq w^{d}, \exists w^{h} / w^{d} \geq\left(w^{h} / w^{d}\right)^{*}$, s.t. $\tau_{\underline{A}}=1 / 2$.

Proof: (i) and (ii) follow directly from $\lim _{w^{h} \rightarrow w^{d}} \varepsilon_{i}^{s}=\varepsilon_{i}^{n}$, (iii) from $\lim _{I^{\min } \rightarrow-\infty}$ $\phi\left(\varepsilon_{i}^{\min }\right)=0$, and (iv) from the fact that $\frac{\partial \tau_{i}^{s}}{\partial\left(w^{h} / w^{d}\right)}>0$ when $\tau_{i}^{s}>1 / 2$. 
Proposition 4 highlights the existence of an important tradeoff in the setting of national educational standards. On the one hand, to be meaningful and effective, such policies need to set standards that are strict enough to raise students' study efforts. As equation (13) indicates, the effect of mandatory standards of educational performance, given by the additional term $\phi\left(\varepsilon_{i}^{\min }\right) \ln \left(w^{h} / w^{d}\right)$, diminishes as standards being contemplated become relatively low (i.e., when the minimum test score $I^{\mathrm{min}}$ is relatively low such that $\varepsilon_{i}^{\min }$ approaches $\left.-\infty\right)$. On the other hand, the higher the educational standards, the greater the likelihood that low ability students will prefer to drop out of secondary school instead of striving to meet the newly introduced requirements. In fact, for any given level of educational standards, $I^{\mathrm{min}}$, the higher is the opportunity cost of meeting these standards (captured by the secondary school education premium, $w^{h} / w^{d}$ ), the higher the dropout likelihood of a student of either type. This leads to the following corollary:

Corollary 1: $\exists$ a sufficiently high supply of college education, $\bar{S}, \bar{S}<1$, s.t when college entrance requirements, which determine the cutoff score $I^{s}$ effectively impose an upper bound on the minimum educational standards, $I^{\mathrm{min}}$, the higher the supply of college education, $\bar{S}$, the smaller the impact of educational standards on student performance.

Proof: Follows from Lemma 1 and Proposition 2. In particular, from the fact that $\lim _{\bar{S} \rightarrow 1} I^{s}=-\infty$ and $\lim _{I^{\min } \rightarrow-\infty} \tau_{i}^{s}=\tau_{i}^{n}$.

This last observation is, of course, due to the fact that college admission requirements impose an upper bound on the politically attainable minimum standards of students performance at the K-12 level. If this were not the case and educational standards could be set at levels above the threshold required for college admission (i.e., $I^{\min } \geq I^{s}$ ), then the implicit constraint that the supply of higher education imposes on optimal student effort would be lifted. In that case, equation (12) would have to be modified such that

$$
E\left[\ln c_{i}\right] \leq E\left[\ln y_{i}\right]=\ln \left(\tau_{i} A_{i}\right)+\left[1-\Phi\left(\varepsilon_{i}^{\min }\right)\right] \ln w^{c}+\Phi\left(\varepsilon_{i}^{\min }\right) \ln w^{d}
$$


and the first-order condition for optimal student effort would then be given by

$$
\gamma_{i}^{s}=\frac{1+\phi\left(\varepsilon_{i}^{\min }\right) \ln \left(w^{c} / w^{d}\right)}{2+\phi\left(\varepsilon_{i}^{\min }\right) \ln \left(w^{c} / w^{d}\right)} ; \quad i=\underline{A}, \bar{A} .
$$

Hence, under the new equilibrium, assuming that parameter values are such that interior solutions exist for both ability types, students exert more study effort in school than they do otherwise-when either no standards exist or are below the relatively low threshold imposed by an abundant supply of college education. Thus in essence, whether the polity is capable of generating and supporting educational standards that are more stringent than those which determine college admissions becomes a crucial issue. Especially so in light of evidence that college admission requirements have continued to creep downward in the United States to such an extent that remedial programs have blossomed on campus. ${ }^{13}$

\section{Further Discussion}

The highly stylized model above abstracts from many potentially relevant issues, some of which have been discussed in the previous literature on educational standards. Most germane among those are how the adoption of educational standards might affect students' interaction and cooperation with their peers, what role imperfections in credit markets may play in educational attainment, and how endogenous wages may affect the incentives to meet educational standards. I now turn to a brief review of these issues focusing on how they might alter the main conclusions presented above.

First, as Bishop (1990, 1996) notes, the absence of national educational standards together with a college admissions process which relies heavily on relative class ranking may cultivate an atmosphere in which students view competition as a zero-sum game. In such an environment, cooperative equilibria in which students minimize study effort and penalize those who deviate from the established group norms may be sustained. Then, the benefit of adopting national standards will accrue from making cooperation impossible by shifting the relevant group of competition from peers in the classroom to the much larger national student cohort. By design, the framework I presented above does

\footnotetext{
${ }^{13}$ See, for example, Finn (1991).
} 
not allow for such potential benefits because, throughout the analysis, I assumed that college admissions depend on scores on tests that all college applicants take. However, if one were to modify the model above in such a way that college admissions depended on a weighted average of scores on standardized tests and relative class ranking, the introduction of national standards may help to eliminate cooperation among students to minimize study effort in this framework as well. That noted, the impact of the supply of educational services and those of college and secondary education premia on optimal student effort would still remain.

Second, there exists a crucial interaction between mandatory schooling laws and the cost of non-compliance with educational standards-the secondary education premium. In particular, mandatory schooling laws could effectively make the cost of non-compliance infinite if, by law, it was not possible for students to dropout of secondary school in response to higher standards. In a similar vein, I have also abstracted from the role of liquidity constraints in determining the demand for college education. Of course, to the extent that credit market imperfections play a role in constraining the demand for college education, the higher education admission process would be less competitive. That in turn would dampen the effect of educational standards on optimal student effort.

Finally, I have also steered clear from how the education premia might respond to changes in optimal student effort when educational standards are introduced. Given the uncertainty involved in who gets admitted to college due to measurement error in standardized tests, it is impossible in this framework to determine exactly what the aggregate units of efficiency labor with different education levels would be under different scenarios. Betts' finding that wage rates at all levels might rise when educational standards are introduced is especially illuminating in this regard, since it makes it more likely that the impact of adopting educational standards on relative wages-and thus, on the education premia-is relatively small.

\section{Conclusion}

Available data suggest that scholastic performance in the United States worsened sharply in the 1960 and 1970s, and despite some progress in the following two decades, it con- 
tinues to be one of the worst among industrialized countries today. Given that the main objective of many school reform agendas is to improve student achievement, it is no wonder that such programs have focused on the introduction of mandatory or voluntary standards of minimum student performance as a potential remedy. In fact, according to Finn, all but five states raised their graduation requirements between 1980 and 1990 . Moreover, one of the main objectives of Goals 2000: Educate America Act, signed into law in 1994, is establishing voluntary national education standards. Despite this trend, however, comprehensive analyses of how and under what circumstances the introduction of educational standards may have a significant positive impact on student effort and achievement remains scarce.

This paper is intended to help fill this void. The model I present above demonstrates that the potential effectiveness of educational standards cannot be determined in isolation, and that it ultimately depends on a combination of other parameters, such as the education premia, availability of higher education and the stringency of standards. The interplay of these parameters turn out to be important because, on the margin, it affects the incentive to meet the standards as well as the cost of not doing so. In particular, a high college premium raises the incentive to finish high school and apply to college, but the marginal benefit of meeting standards depends on the high-school education premium. Thus, ceteris paribus, the setting of higher standards may not affect educational outcomes in a significant way when the high-school education premium is relatively low. The accessibility of college education also matters. When the supply of college education is sufficiently abundant that college admissions is not a competitive process, students' incentive to make their best effort diminishes, and in that case, the role of education premia-and therefore of standards-as incentives may be limited. Finally, the stringency of standards affects student effort, although its ultimate impact depends on other factors such as the education premia and the accessibility of higher education. 


\section{References}

Autor, D., A. Krueger and L. Katz. (1998). "Computing Inequality: Have Computers Changed the Labor Market?," Quarterly Journal of Economics, 113 (4), November, 1169-1213.

Betts, J. R. (1998). "The Impact of Educational Standards on the Level of Distribution of Earnings," American Economic Review, 88 (1), March, 266-75.

Bishop, J. (1990). "Incentives for Learning: Why American High School Students Compare So Poorly to their Counterparts Overseas," in Bassi, L. J. and D. L. Crawford, eds. Labor Economics and Public Policy, Research in Labor Economics, vol. 11. (London: JAI Press).

Bishop, J. (1996). "Signaling, Incentives, and School Organization in France, Netherlands, Britain, and the United States," in Hanushek, E. and D. Jorgenson, eds. Improving America's Schools. (Washington, D.C.: National Academy Press).

Coleman, J. S. et al. (1966). Equality of Educational Opportunity. (Washington, D.C.: U.S. G.P.O.).

Costrell, R. M. (1994). "A Simple Model of Educational Standards," American Economic Review, 84 (4), September, 956-71.

Finn, C. E., Jr. (1991). We Must Take Charge: Our Schools and Our Future. (New York: Free Press).

Juhn, C., K. M. Murphy and B. Pierce, 1993, "Wage Inequality and the Rise in Returns to Skill," Journal of Political Economy, vol. 101, no. 3, 410-42.

Lapointe, A. E., N. A. Mead and G. W. Phillips. (1989). A World of Differences: An International Assessment of Mathematics and Science. (Princeton, N. J.: The Educational Testing Service).

Murphy, K. M., 1996, "Skills and Earnings Inequality: The Supply Side," AEI Seminar Series on Understanding Economic Inequality.

National Commission on Excellence in Education. (1983). A Nation at Risk. (Washington D. C. : U. S. Department of Education). 
Ravitch, D. (1983). The Troubled Crusade: American Education 1945-1980. (New York: Basic Books).

Ravitch, D. (1995). National Standards in American Education: A Citizen's Guide. (Washington D. C. : The Brookings Institution).

Sizer, T. R. (1995). Debating the Future of American Education: Do We Need National Standards and Assessments? Brookings Dialogues in Public Policy. D. Ravitch, ed. (Washington D. C. : The Brookings Institution). 
Figure 1:

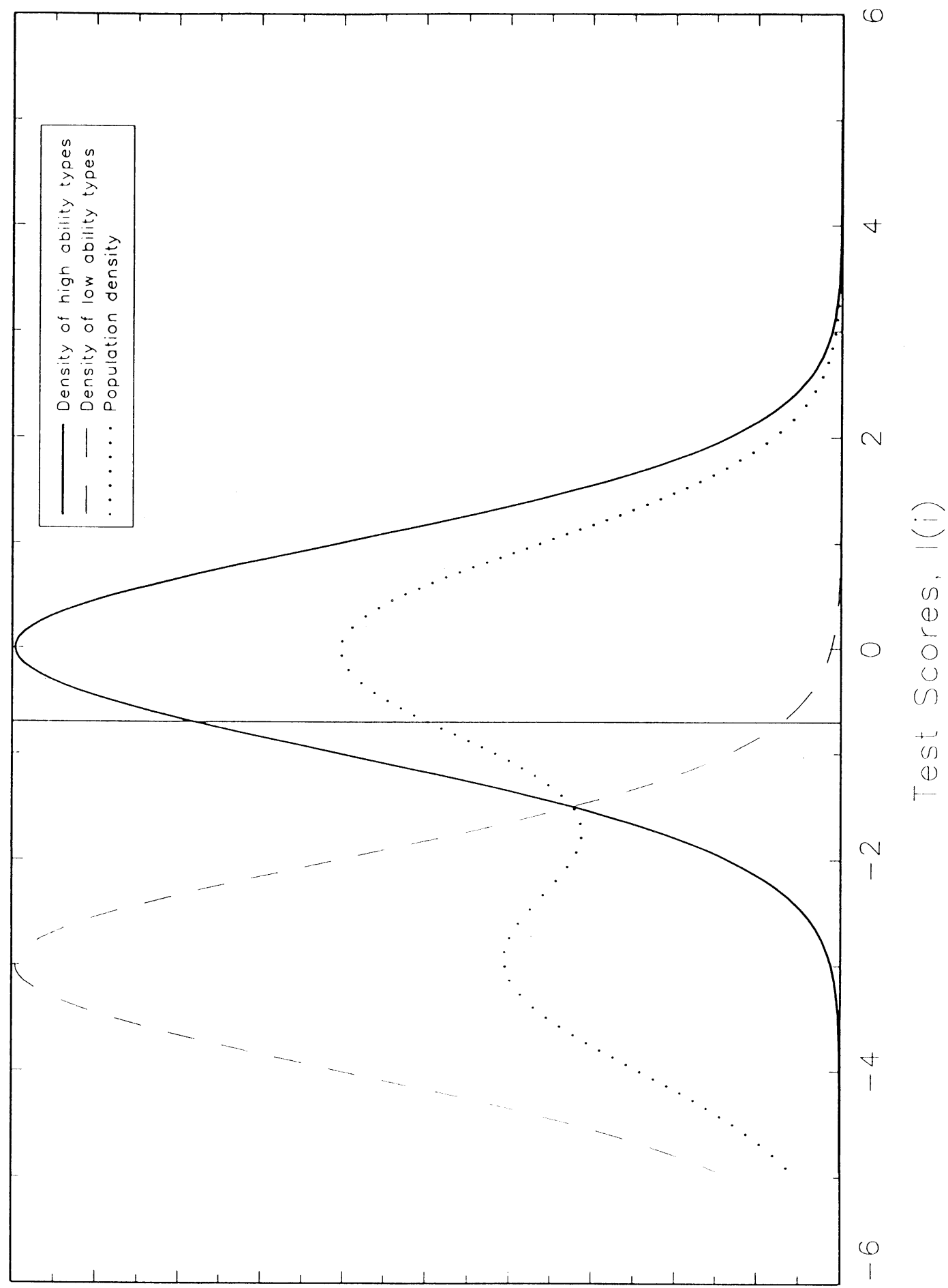

KfIsuan 
Figure 2:

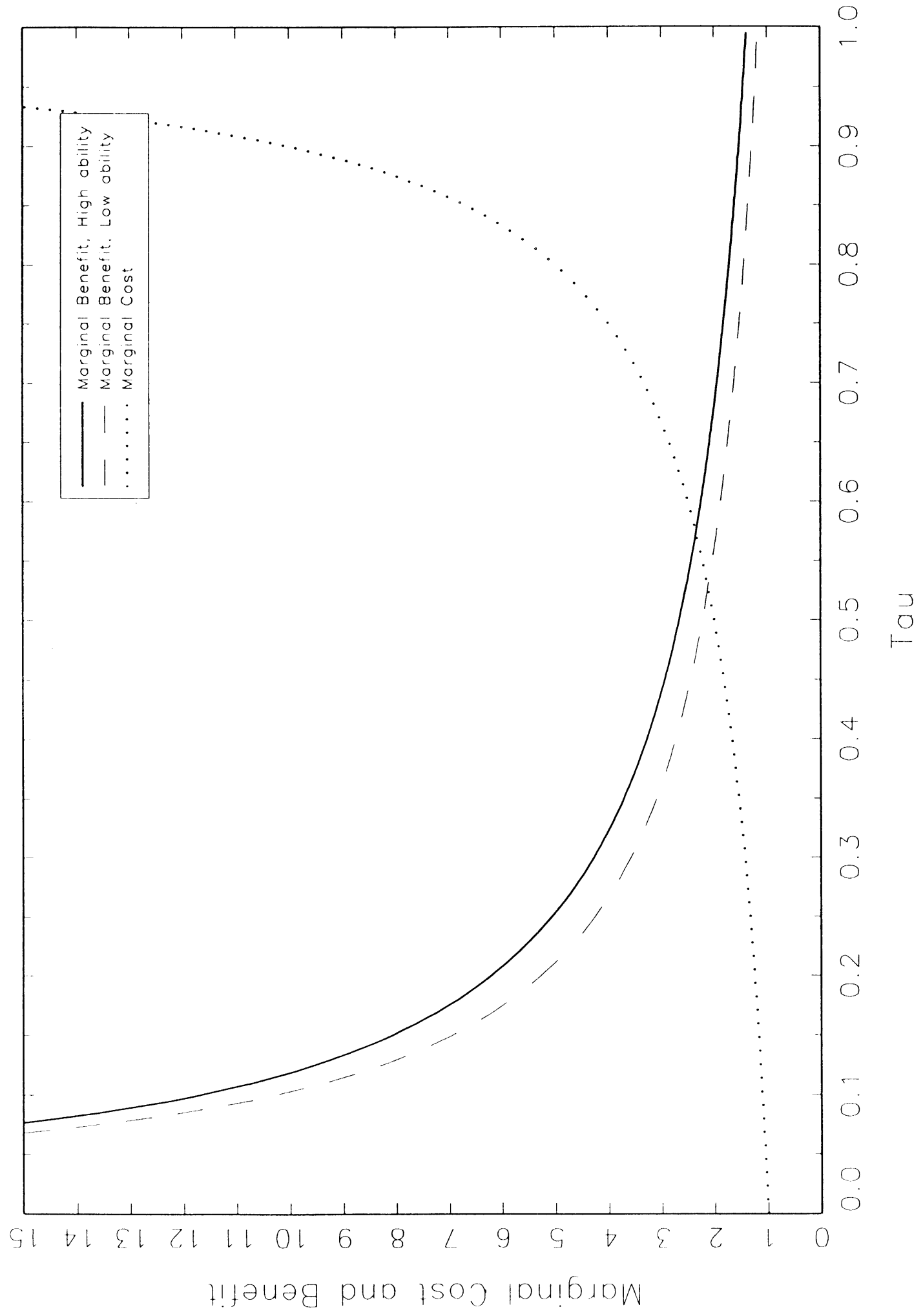

